\title{
RESPIRATORY SYSTEM AND PULMONARY INTERSTITIAL DISEASE DUE TO CIGARETTE SMOKE IN RADIOLOGICAL ASPECTS
}

\author{
Devy Trianne Putria ${ }^{a}$ Bambang Soeprijanto ${ }^{b}$
}

${ }^{a}$ Corresponding Email:dphi_tp@yahoo.com

${ }^{a}$ Resident of Pulmonology and Respiratory Medicine, Faculty of Medicine, Airlangga University, Dr. Soetomo Hospital Surabaya.

${ }^{b}$ Lecturer at the Department of Radiology, Faculty of Medicine, Airlangga University, Dr. Soetomo Hospital Surabaya

\begin{abstract}
Smoking is a risk factor for disease that contributes the most to lung and respiratory diseases. Lung disease related with cigarette smoke can be classified as COPD (Chronic Obstructive Pulmonary Disease) and several types of interstitial lung disease such as pulmonary langerhans cell histiocytosis, bronchiolitis, desquamative interstitial pneumonitis and interstitial fibrosing lung disease. This literature review aims to shed a light that cigarette smoke not only causes inflammation and damages the epithelium of the large respiratory tract but also the small airways and lung parenchyma. COPD (including chronic bronchitis and emphysema) is one of the most common lung diseases and causes death due to smoking. Lung disease related with smoking in addition to providing a mass image can also provide an interstitial picture such as Langerhans cell histiocytosis, bronchiolitis, desquamative interstitial pneumonitis and interstitial fibrosing lung disease. radiological picture in lung disease caused by cigarette smoke can also occur in combination. Although the radiological picture / image of computerized tomography can provide adequate information, a comprehensive diagnostic by combining clinical symptoms and histopathological features will be quite meaningful, especially for overlapping cases.
\end{abstract}

\section{Introduction}

Smoking is a risk factor for disease that contributes the most to lung and respiratory diseases. Lung disease related with cigarette smoke can be classified as COPD (Chronic Obstructive Pulmonary Disease) and several types of interstitial lung disease such as pulmonary langerhans cell histiocytosis, bronchiolitis, desquamative interstitial pneumonitis and interstitial fibrosing lung disease. ${ }^{1}$ The death rate from smoking continues to increase every year and it is estimated that 3 million deaths in 1990 will continue to increase to 10 million deaths in 2025. ${ }^{2}$

\section{Cigarettes and Discussion}

Cigarettes are grouped into several types, namely based on cigarette wrapping materials, raw materials or cigarette contents, the process of making cigarettes, and the use of filters on cigarettes. Based on the wrapping material cigarettes are distinguished into : klobot is a cigarette wrapping material in the form of corn leaves; kawung is a cigarette whose wrapping material is in the form of palm leaves; cigarettes are cigarettes whose wrapping material is paper; and cigars are cigarettes whose wrapping material is in the form of tobacco leaves. Based on the raw material or the content of cigarettes, it is divided into: white cigarettes, namely cigarettes whose raw material only contains tobacco leaves which are given a flavour to get a certain taste and aroma effect; kretek cigarettes are cigarettes whose raw materials are a mixture of tobacco leaves with cloves flavored; klembak cigarettes are cigarettes whose raw materials are a mixture of tobacco leaves with cloves and frankincense and given flavors to get a certain flavor and aroma effect. Based on the manufacturing process, cigarettes can be divided into: sigaret kretek tangan (SKT) or hand-rolled cigarette is a cigarette whose manufacturing process rolled by hands or using simple tools; sigaret kretek mesin (SKM) or machine-made kretek cigarettes, namely cigarettes that are manufactured using machines. Based on the use of cigarette filters, it is divided into; filter 
cigarettes, namely cigarettes with a cork at the base; non-filter cigarettes, namely cigarettes with no cork at the base. $^{3}$

Cigarette combustion smoke is divided into two parts, namely the main smoke (mainstream smoke) smoked directly by smokers and sidestream smoke found at the end of the cigarette part. ${ }^{4}$



Fig. 1. Illustration of a burned cigarette. ${ }^{4}$

The main smoke is divided into solid phase or particulate solid phase (tar) and gas phase or gas phase (toxic gas, volatile organic compound (VOC), free radical, and so on). ${ }^{5}$ Cigarette smoke is a toxic substance and is a mixture of more than 4000 chemicals. At least 250 hazardous materials and 69 carcinogenic substances are contained in them, each blow containing approximately $10^{15}$ free radicals. ${ }^{6}$

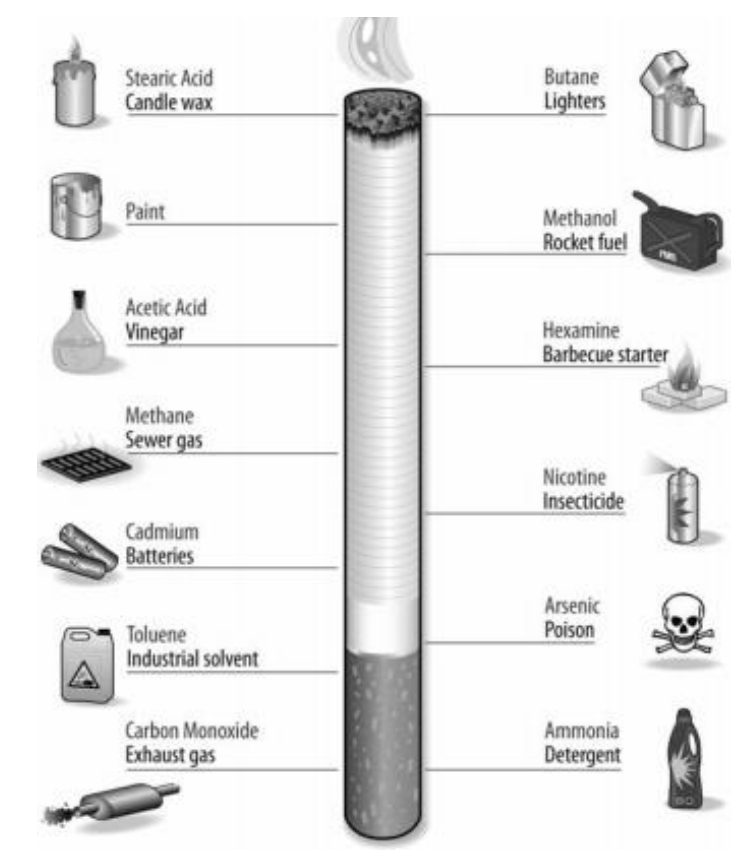

Fig. 2. Cigarette components 6 
Every time a person smokes a cigarette, a person is at risk of exposure to at least 45 types of toxic chemicals. Some important but dangerous compounds include lutidin, rubidin, formaldehyde, carbolic acid, metalimin, akreolite, kolidin, viridin, arsenic, formic acid, nicotine, hydrogen sulfide, pirel, furfurol, benzopiren, methyl alcohol, hydrocyanic acid, corodin, arnonia, methane, carbon monoxide, and pyridine. Benzopirene and lutidine are derived from tobacco tars. Colidine can cause paralysis and gradually result to the death. Carbolic acid and hydrocyanic acid are dangerous poisons. Hydrocyanic acid can kill in a matter of minutes. Methyl alcohol can cause blindness, while carbon monoxide competes with oxygen to bind to hemoglobin in the blood. ${ }^{7}$

\section{Respiratory response to cigarette smoke inhalation}

The respiratory extends from the trachea to the alveoli and consists of about 23 branched generations.

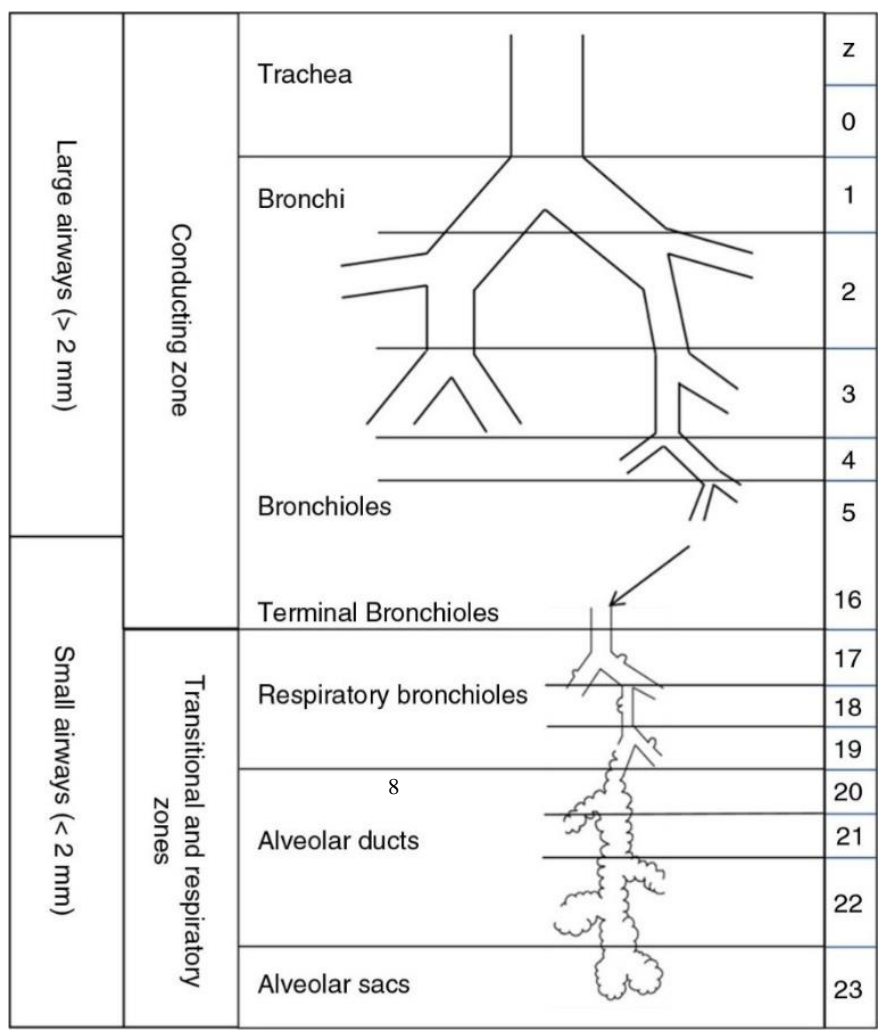

Fig. 3. Respiratory generation

The deposition of cigarette smoke particles depends on their size, breathing pattern and the relationship between lung structure and function. The average size of cigarette smoke particles is $0.1-0.5 \mu \mathrm{m}$, so they can reach small airways. About 10-30\% of these particles will be deposited in the lungs, from this percentage about $40-90 \%$ will be deposited in the air exchange region. Larger particles will be deposited by crashing into the airway branching while smaller particles will be deposited by settling in the airway area with a slower flow, namely in the small airway. ${ }^{9}$

In healthy individuals, the complex system of host defense mechanisms limits the entry of unknown substances through the mucosal surface and removes unknown particles deposited along the airways and alveoli. This mechanism includes the anatomical barrier of the airway, clearance activity through the cough reflex: and the mucociliary apparatus as well as several other immunological and non-immunological substances. The proximal part of the tracheobronchial branching is limited by cilia cells which are mucociliary escalators that are in charge of removing inhaled particles. Smoking habits will trigger an increase in the number of abnormal cilia so that it can interfere with the mucociliary clearance function. The airways after the 14th generation do not have this protection, so they are more susceptible to the effects of inhaled particles, especially $0.5-5 \mathrm{~mm}$ particles such as cigarette smoke particles. After the first inhalation of cigarette smoke, the initial event that occurs is a change in the epithelial cell barrier causing airway inflammation. ${ }^{10,11}$ 


\section{The impact of cigarette smoke on the lungs and respiratory tract \\ 4.1 Epithelial damage and airway inflammation}

The direct effect of cigarette smoke accompanied by indirect damage that is a result of inflammatory cells causing changes in the epithelial airway i.e. skuamous epithelial metaplasia, goblet cell metaplasia, mucosal gland hyperplasia, changes in mucosal clearance and fibrotic changes. The presence of an inflammatory process can also result in air flow obstruction because inflammation causes bronchoconstriction by releasing inflammatory mediators that can act directly on bronchial smooth muscle. Several types of inflammatory cells play a role in this process. ${ }^{9}$

Cigarette smoke will increase the excretory function of the airway epithelium. There was an increase in the concentration of peptides, amines, expression of MHC and proinflammatory cytokines: IL-8, IL-6, and TNF-a. The increase in inflammatory cells in the airway wall is a result of increased expression of adhesion molecules, increased permeability and loss of cellular integrity. ${ }^{12}$

The occurrence of goblet cell metaplasia plays an important role in the occurrence of airway obstruction triggered by cigarette smoke in two ways: first by producing excess mucus that can change the surface tension in the lining of the airway, cause the peripheral airway to become unstable and close; by inducing lumen closure through the formation of mисоus plug in the peripheral airway. Cigarette smoke will also activate epidermal growth factor receptor (EGFR) which regulates mucin production in smokers. Skuamous cell metaplasis cause increased secretion of IL-1 resulting in increased secretion of transforming growth factor-B (TGF-B) which plays a role in the onset of peribronkial fibrosis. ${ }^{12,13}$

Examination of broncoalveolar (BAL) rinse fluid and analysis of the sputum of smokers with chronic airway obstruction showed that there was an increase in neutrophils in the airway lumen and also found a positive correlation between the number of neutrophils and a decrease in FEV1 value per year. Although there has been no evidence of a direct relationship between nicotine levels and airway obstruction, nicotine is a chemotactic factor against neutrophils, the first cells recruited to smoke-induced airway inflammation, so nicotine plays an important role in initiating pulmonary response that causes obstruction airway because nicotine can change capillary endothelial cells or neutrophils directly, or change the bond between neutrophils and endothelium. Adhesion of neutrophils with capillary endothelial cells becomes critical causing recruitment of neutrophils from the circulation to the site of inflammation. Apart from having a role in the recruitment and activation of neutrophils, bronchial epithelial cells also increase the survival of neutrophils in vitro by releasing granulocyte-macrophage colony-stimulating factor (GM-CSF), indicating that epithelial cells can change the cellularity of the inflammatory response in the acute phase of injury due to cigarette smoke, although the epithelial cell layer is still intact. ${ }^{14}$

Another cell involved in the process, airway inflammation induced by cigarette smoke is $\mathrm{T}$ lymphocyte cells. Bronchial biopsy studies taken via bronchoscopic procedures or from surgical specimens show that $\mathrm{T}$ lymphocytes infiltrate the epithelium and submucosa of patients with mild to moderate airway obstruction. along with alveolar macrophages and eosinophils. Through immunohistochemical examination, it was explained that in chronic airway obstruction, the inflammatory process is more due to CD8 + cell lymphocytes, which are different from those found in asthma, which are dominated by CD $4+$ cell lymphocytes. CD8 + lymphocytes are found in all pulmonary compartments, including the large airways, small airways and pulmonary parenchyma. In the bronchial biopsy of smokers with and without chronic airway obstruction, O'Shaugnessy et al. Found that when airway obstruction occurred, neutrophils and CD8 + lymphocytes increased in number and in proportion to decreased lung function. These researchers suggest that individuals with a genetically higher CD8 + cell population may be more susceptible to cigarette smoke-induced increased CD8 + cell recruitment. This explains why chronic airway obstruction occurs in only a minority of smokers. ${ }^{15,16}$

The infiltration function of lymphocytes into the lungs of smokers is not yet widely known, but lymphocytes play an important role in inflammatory responses. Lymphokin produced by activated $\mathrm{T}$ cells, including interferon-gamma (IFN-y), interleukin-4 (IL-4), interleukin-5 (IL-5) and GM-CSF, is a key mediator in cellular immune response. These lymphokines are active in regulating many other cells, such as eosinophils; neutrophils; mast cells; monocytes and are able to activate and degranulate these effector cells. ${ }^{15,16}$

Dendritic cells, cells that present antigens, are tasked with connecting the innate immune system with the adaptive immune system. The dendritic cell count increases in the epithelium and tunica 
adventisia of the small airway of a person with air flow obstruction due to cigarette smoke. Dendritic cell maturation is related to the severity of airflow resistance. Apart from dendritic cells, mast cells are also found in smooth muscle and alveoli of the small airways. Mast cells play a role in fibrotic processes in the airways. ${ }^{17}$

\section{Reducing the function of macrophages}

Macrophages, with their phagocytic function, are the main cell population in the lungs that play a role in the first-line cellular defense against pollutants. Cigarette smoke causes the entry of alveolar macrophages into the lumen of the airway. There was an increase in the number of alveolar macrophages in the broncoalveolar (BAL) rinse of smokers by 2-3 times compared to nonsmokers. Macrophages in smokers' lungs, even though they are more numerous, but they are less mature, so that their ability to present antigens is impaired and their metabolic activity is weak. The chronic effect of cigarette smoke will lead to increased secretion of cytokines and chemoatractants against other inflammatory cells. The action of inflammatory cells causing damage to the airways is the result of a combination of several inflammatory actions. At the beginning of the inflammatory reaction involves neutrophils which are then followed alveolar macrophages on the epithelial surface. These cells cause damage to epithelial cells and interscial protein structures, which will be processed into peptides and recognized by T cells. Once activated, the $\mathrm{T}$ cells will recruit nettrophils and other alveolar macrophages to the inflammatory site. CD8+ cells are capable of releasing IL-5, eosinophil chemoattractant and cytokine activators, as well as producing IL-8, netrophilic strong chemoattractant. With this mechanism CD8 + cells play an important role in regulating the entry of eosinophils and neutrophils in cigarette smoke-induced inflammation of the small airways. ${ }^{9}$

\section{Inflammation of the lung parenchyma}

The mechanism for neutrophil recruitment is still not fully understood, but it appears that the process is influenced by the loss of the neutrophil's capacity to deform, an important mechanism that allows these cells to pass through pulmonary capillaries along with other factors. This decreased deformability will delay neutrophils from passing through the alveolo-capillary membrane, causing the release of neutrophil elastase and reactive oxygen radical (ROR). Neutrophil elastase released by neutrophils will cause damage to the alveolar walls and mucus hypersecretion so that the diameter of the small airway decreases and ultimately causes air flow limitation, In addition to neutrophils, cigarette smoke also contains high concentrations of ROR and substances that produce ROR. Reactive oxygen radical $(R O R)$ is formed at the end of a cigarette butt which is burned at high temperatures and is also found in sidestream smoke. These substances will then cause tissue destruction through an imbalance of protease-antiprotease and oxidant-antioxidants. Based on this theory, in a normal situation proteolytic enzymes (elastase, cathepsin G) from neutrophils and matrix metalloprotease-12 (MMP-12) from macrophages will be neutralized by the anti-protein protection mechanism (al-antitrypsin). However, in smokers, this antiprotease activity is disrupted by the oxidation of al-antitrypsin which is caused by the action of free radicals from cigarette smoke. As a consequence, this proteolytic activity destroys the lung parenchyma by destroying elastin, increasing neutrophil recruitment and collagen deposition.50 Saetta et al. reported that the degree of airway inflammation in smokers was associated with loss of alveolar integrity (alveolar attachments). Saetta et al. stated that the products of these inflammatory cells can weaken the alveolar tissue and cause rupture at a point where it attaches to the outer wall of the airway and mechanical stress becomes maximal. Without a counterbalance, proteolytic activity causes pulmonary parenchyma emphysema. This parenchyma destruction combined with inflammation and remodelling of the airways will decrease pulmonary elastic recoil and increase peripheral airway resistance, two main factors responsible for the decrease in maximum expiry flow in a smoker's lungs. ${ }^{18,19}$

5. Airway and interstitial disease due to cigarette smoke

5.1 Respiratory Bronchiolitis $(\mathrm{RB})$

Respiratory Bronchiolitis-Associated Interstitisl Lung Disease (RBILD) is a disease of Respiratory Bronchiolitis ( $R B$ )attributed to smoking, was first discovered in 1987 through an autopsy study of 19 young smokers without respiratory symptoms. Myers et al described the significant lung pathological findings in heavy smokers, namely the presence of lung inflammation, restriction damage and interstitial radiological features. ${ }^{20,21}$ Fraig et al's study through lung biopsy, stated that RBILD was also found in former smokers who had quit since 5 years. ${ }^{22}$

The occurrence of bronchiolitis can be associated with the physiological response of the lungs and airways to smoking because there are no studies that suggest that the disease is found in nonsmokers. 
The presence of profuse brown pigmented macrophages which are sometimes accompanied by fibrosis of the peribronchial area that increases with the length of smoking history is a characteristic of smokinginduced RB. The brown pigmented macrophages will decrease and can disappear in 3 to 10 years, although some are more than a decade. ${ }^{20}$

\subsubsection{Patology}

Although the histopathological features of RBILD are difficult to distinguish from RB, the most commonly found in RBILD are alveolar macrophages with brown pigmentation and finely granular pigmentation (which can be the residue of cigarette smoke) that accumulates between the respiratory bronchioles and alveoli. Chronic infiltration of inflammatory cells generally occurs in the bronchial area and adjacent alveolar walls and can lead to thickening of the septum due to collagen deposition and hypeplasia of type II pneumocytes. The lung parenchyma image is generally normal although emphysematus may occur. ${ }^{22,23}$

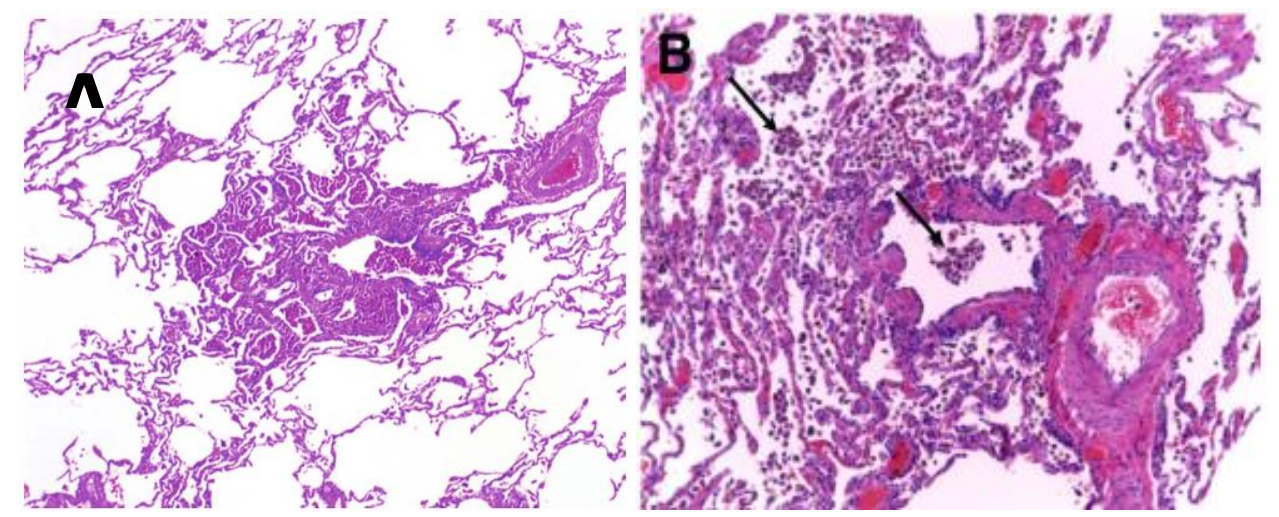

Fig.4. Histopatology $R B$ dan RBILD (A: Respiratory Bronchiolitis : alveolar appears around the broncholus there is infiltration of macrophage cells ; B: Respiratory Bronchiolitis-Associated Interstitisl Lung Disease) : alveolar macrophages with bright brown granules filling the cytoplasm as well as the presence of slight interstitial infiltration of lymphocytes. ${ }^{20,28}$

\subsubsection{Clinical Picture}

Clinical picture of Respiratory Bronchiolitisgenerally are asymptomatic, but otherwise on Respiratory Bronchiolitis-Associated Interstitisl Lung Disease severe shortness of breath occurs especially with exertion, persistent and generally unproductive cough that can last from weeks to months. There may also be chest pain and weight loss, although they are rarely reported ${ }^{20,21,23}$ Pulmonary function tests on RB are generally normal, but obstructive abnormalities may also be present, whereas in RBILD obstruction and restriction abnormalities are reported. Diagnosis in RBILD is more based on clinical symptoms and radiological findings of HRCT, because in a minority of patients, pulmonary function tests is normal. ${ }^{24}$ Finding through bronkhoalveolar Lavage (BAL) very useful in differentiating from hypersensitivity pneumonia and other idiopathic interstitial pneumonia, which is an increase in the number of macrophages and lymphocytosis in RBILD.. ${ }^{25}$

\subsection{3 radiological picture}

The abnormality image of HRCT on $R B$ reported by Remy-Jardinin in 98 active smokers, parenchymal micronodule image was $27 \%$, opacity patchy ground-glass are $21 \%$, lobular area of decreased attenuation as much as $21 \%, 34 \%$ and $21 \%$ with emphysema image. $90 \%$ description of HRCT in RBILD in the form of thickening of proximal to segmental airway walls with other images of thickening of peripheral bronchial walls, centrilobular nodules, patchy ground-glass opacity, emphysema and patchy areas of decreased attenuation. Total $23 \%$ of description is also accompanied by the air trapping segmental. ${ }^{20}$ The diagnosis of RBILD based on HRCT is principally description of smokingrelated inflammation with a significant diffuse feature of the lung. The abnormalities found in HRCT are very limited but quite compatible, so that it is more indicative of a Respiratory Bronchiolitis, therefore it must be combined with clinical symptoms and the severity of pulmonary function in the diagnosis. ${ }^{20,26}$ 

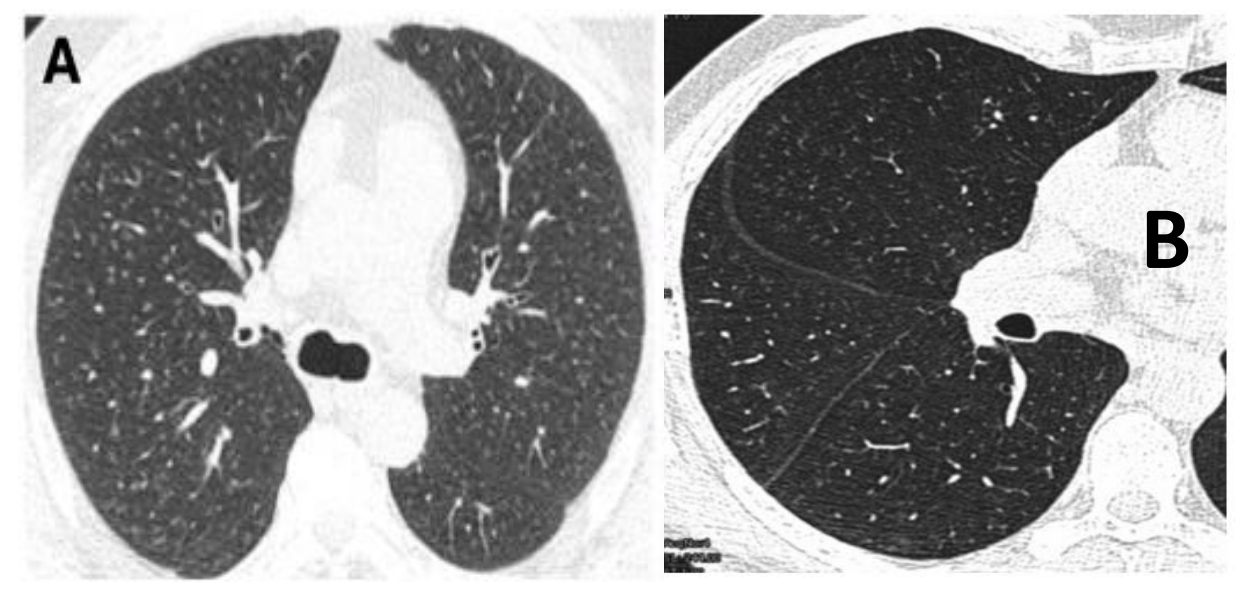

Fig. 5. HRCT RBILD micronodular pattern (A: there are nodul-nodul centrilobular ; B: several smooth nodules along with groundglass density). ${ }^{20,28}$

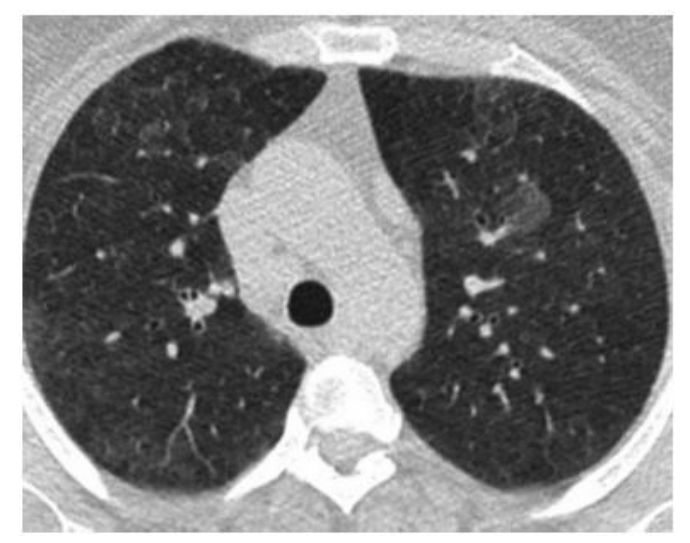

Fig. 6. The opacity of the patchy groundglass pattern on the upper lobe associated with macrophage infiltration and the walls of the subsegmental bronchi appear slightly thickened on the RBILD. ${ }^{20}$

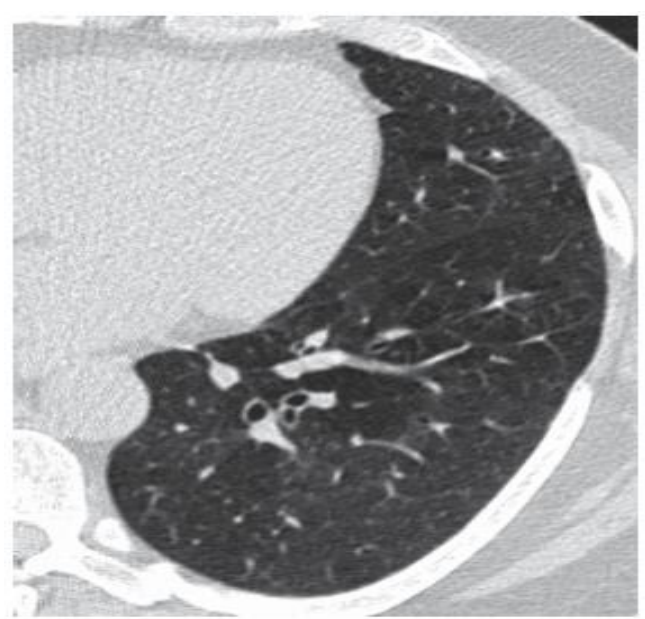

Fig. 7. There is a slight decrease in the density of the lung parenchyma at the bottom. ${ }^{20}$ 


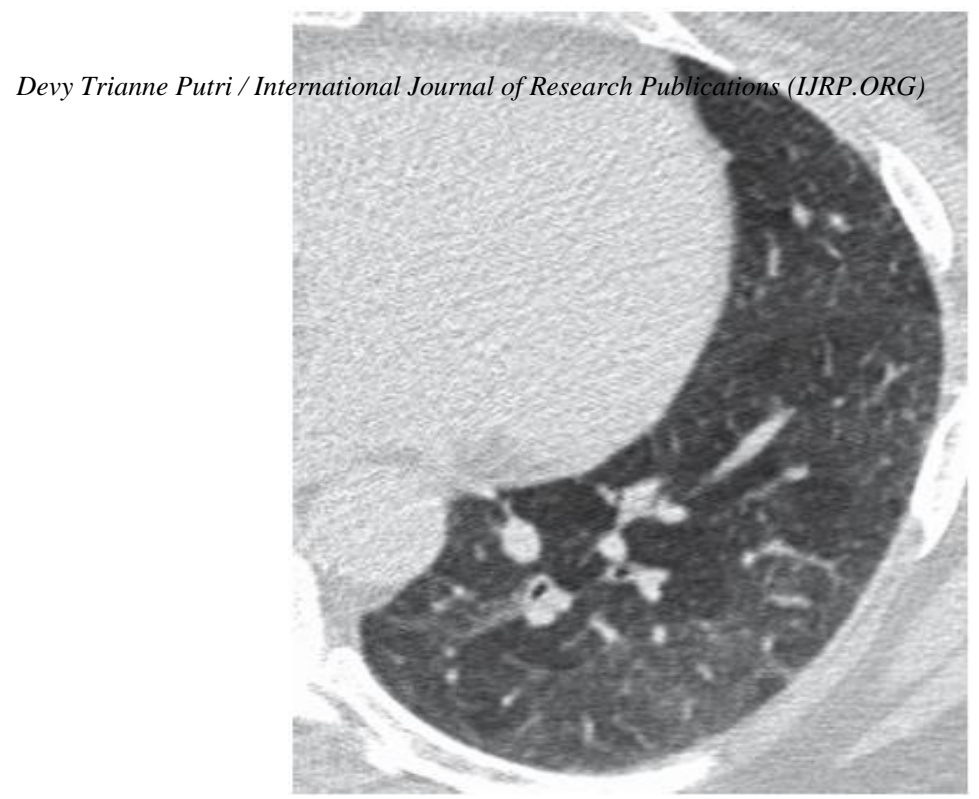

Fig. 8. HRCT when the expiry of RBILD obtained mosaic pattern which is an air trapping in the small airway. ${ }^{20}$

\subsection{Desquamative interstitial pneumonia}

Desquamative Interstitial Pneumonia (DIP) It was first introduced by Liebow in 1965. As many as $90 \%$ of DIP sufferers are smokers, but DIP can also be found in people with pneumoconiosis, drug allergies, congenital metabolic diseases. ${ }^{20}$

\subsubsection{Patology}

Histopatology overview DIP is the accumulation of intra alveolar macrophages diffuse / spread, pneumocyte cell hyperplasia type II and in some cases encountered septum (wall) alveolar can be slightly thickened. Macrophages found are often the same brown-piped as in RBILD, the difference only on the properties of infiltration spread (diffusion) from macrophages that are more subpleura or random. ${ }^{20,21}$

\subsubsection{Clinical Pictures}

The clinical pictures of DIP sufferers are severe shortness of breath, unproductive cough and sometimes fatigue and weight loss may also occur. ${ }^{20,28}$ Lung function tests showed restrictive abnormalities. BAL examination profile is not specific and shows variations in the increase in lymphocytes, neutrophils and eosinophils. ${ }^{25}$

\subsubsection{Radiological Picture}

Radiological picture of DIP often non-specific. Although rare however the bilateral groundglass opacity overview sometimes symmetrical, peripheral and more commonly found in the lower zones can be found in DIP. Some cases have been encountered with overview of irreguler linear oppasity in basal sections related to distortion of anatomical structures, traction bronchiectasis and small peripheral cystic spaces (can occur due to dilated bronchioles and alveolar ducts). Because DIP diagnostic through radiological imaging especially HRCT is not specific, it is necessary to biopsy PA histo to confirm the diagnosis. ${ }^{20}$

Fig. 9. (A) PA position piston photo, (B) Thoracic CT scan and (C) histopathology of DIP showing groundglass opacity and cystic changes of the lower, middle and lingular lobes on HRCT and the presence of large numbers of macrophage cells in the cytoplasm, lymphocyte infiltration and mild fibrosis. $^{28}$

\section{Langerhans cell histocytosis}

Pulmonary Langerhans Cell Histocytosis $(P L C H)$ is a disease in young smokers. This disease is characterized by the presence of abnormal peribronchial Langerhans cells. PLCH is another form of diffuse lung disease related with smoking. ${ }^{27}$

\subsubsection{Patology}

Generally langerhans cell found on the surface of the epithelium, especially the skin, but on normal lung histopathological examination, Langerhans cells are rarely found unless the lung is exposed to cigarette smoke, the Langerhans cell count will increase. The change in the lung epithelium due to cigarette smoke makes Langerhans cells proliferate and change shape, which initially consists of bronchosentric nodules mixed with eosinophils, nitrophils and lymphocytes which develop into cavities to become cystic and can change into stellate scars according to the severity of the disease.. ${ }^{20}$
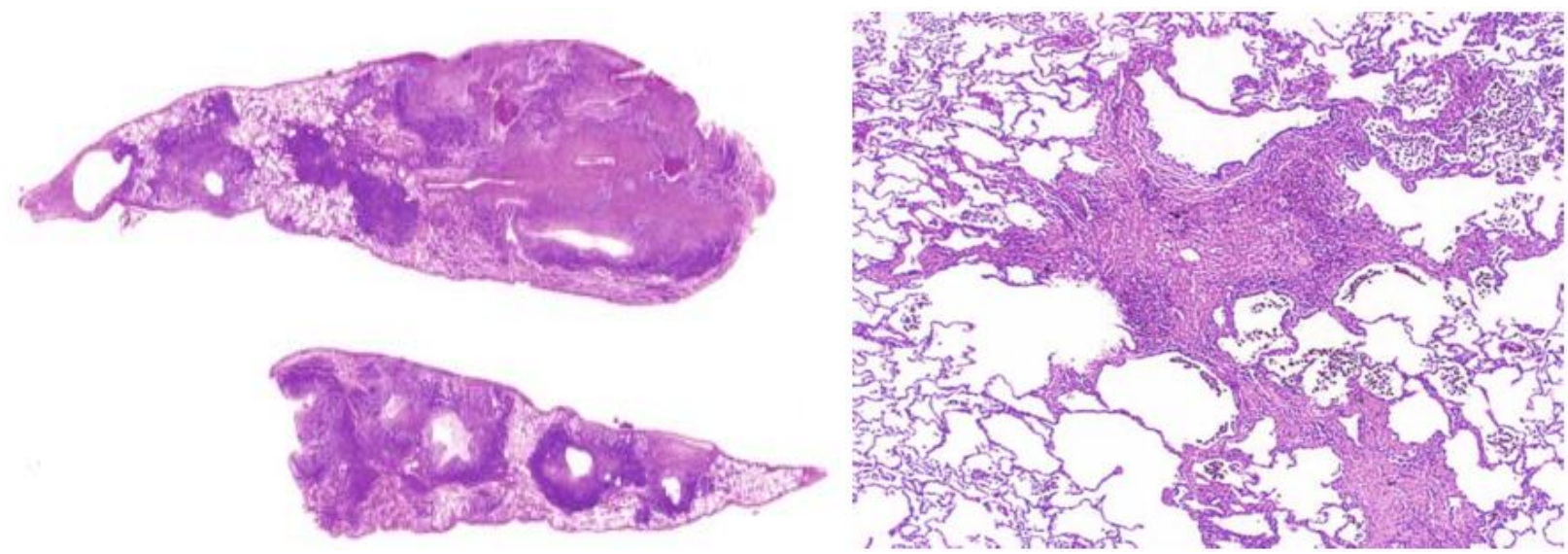

Fig. 10. Histopatology from Langerhans cells. ${ }^{20}$

\subsubsection{Clinical Pictures}

Because PLCH attacks young smokers, respiratory clinical symptoms such as tightness and cough are not specific, sometimes accompanied by pneumotorak, fever or weight loss. ${ }^{20,28}$

\subsubsection{Radiological Picture}

Radiological picture with the most common classic CT scans is $2 \mathrm{~cm}$ rem shadows with sizes varying from micronodular to about $1 \mathrm{~cm}$ in the middle zone area and larger sizes ranging from millimeters to $2 \mathrm{~cm}$ in the middle and upper zones accompanied by cavitation nodules. The smallest nodule and micronodular cavities can be detected with HRCT. Another pattern of HRCT in PLCH is ground-glass opacity which is sometimes accompanied by centrilobular and paraseptal emphysema and can be accompanied by fibrobullous destruction. ${ }^{27}$ 


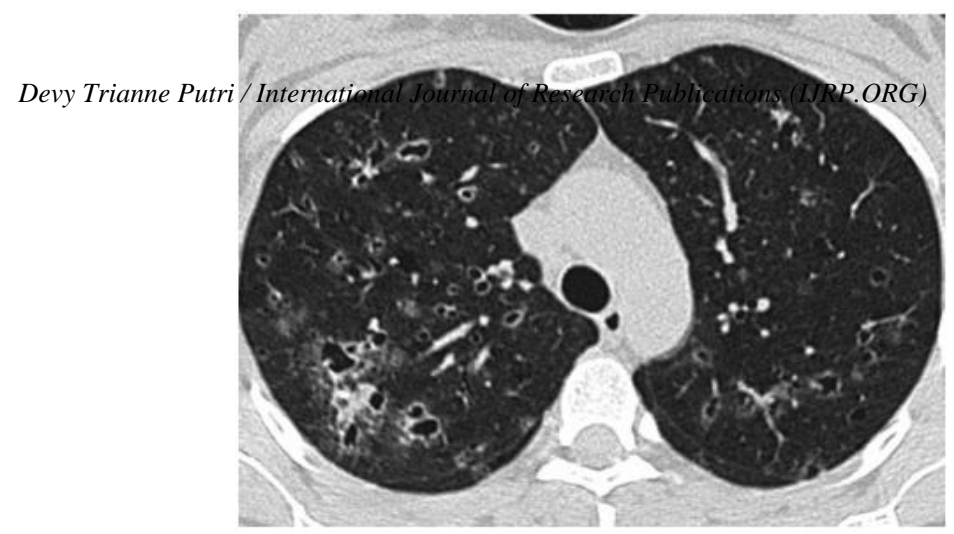

Fig.11. HRCT PLCH : there were cavitated nodules. ${ }^{20}$

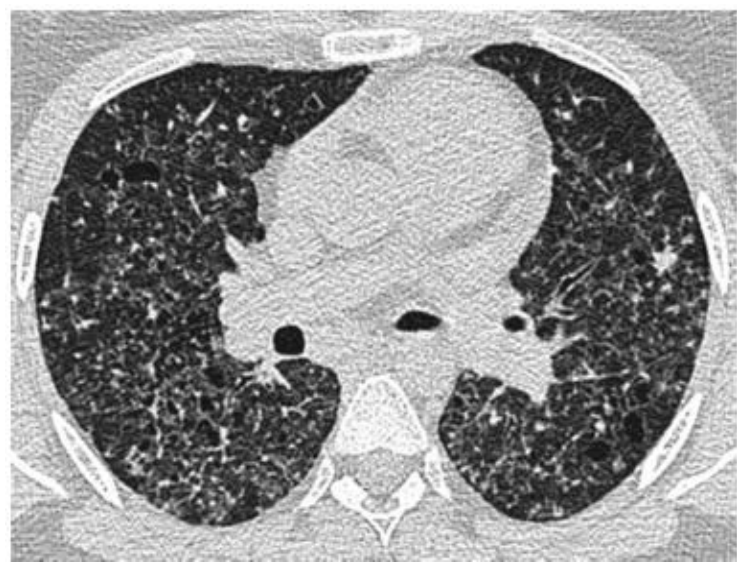

Fig. 12. HRCT PLCH : there is a micronodular pattern, some with large nodules with reticular elements and some cystic airspaces with thin walls. ${ }^{20}$

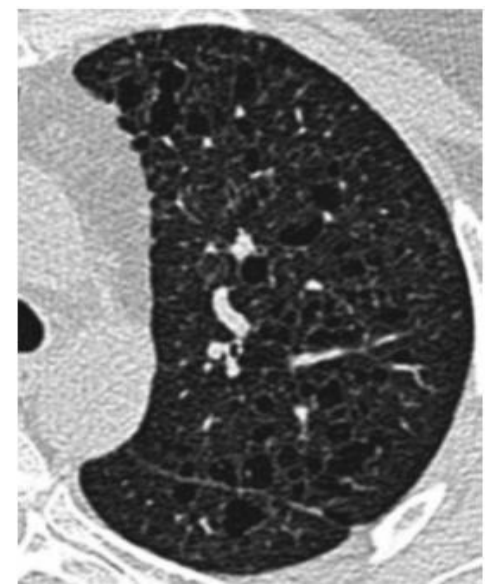

Fig. 13. HRCT PLCH : some cystic airspace with thin walls appear. ${ }^{20}$

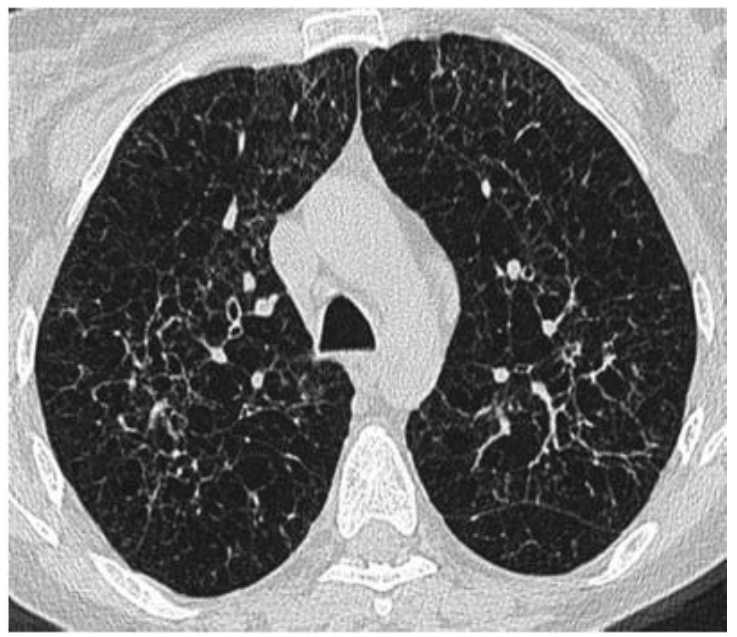


Fig. 14. HRCT PLCH the most severe: there was fibrobullous damage to the pulmonary parenchyma that was evenly distributed..$^{20}$

\subsection{Interstitial Fibrosis}

Airspace Enlargement with Fibrosis (AEF) also known as Smoking-Related Interstitial Fibrosis (SRIF) occurs because cigarette smoke causes fibrosis of the alveolar wall. The severity of the disease can give a picture of fibrosis from sparse to diffuse to dense with eosinophilic collagen, pausiseluler. ${ }^{20,28}$

\subsubsection{Patology}

The histopathological overview found is fibrosis which is limited to subpleural and peribronkial interstitium. Images of smooth muscles that experience hypertrophy appear to dominate and the presence of dense eosinophilic collagen. ${ }^{28}$

\subsubsection{Clinical Pictures}

Although most have relatively fixed clinical symptoms and for a long time, but often clinical such as tightness that increases progressively especially during activity and can be accompanied by cough especially when accompanied by clinical interstitial pneumonia can occur. ${ }^{28}$

\subsubsection{Radiological Picture}

radiological picture from AEF is subpleural sparing thinwalled cyst (TWCS) related with reticular presence and groundglass opacity. The features of TWCs associated with smoking are almost the same as those of a typical honeycomb in disease Idiopathic Pulmonary Fibrosis (IPF). Cyst of AEF is cyst thin-walled (less than $1 \mathrm{~mm}$ ) with a predominant distribution in the upper and upper and middle lobes of the lower lobe towards the center (away from the pleura)..$^{20,28}$

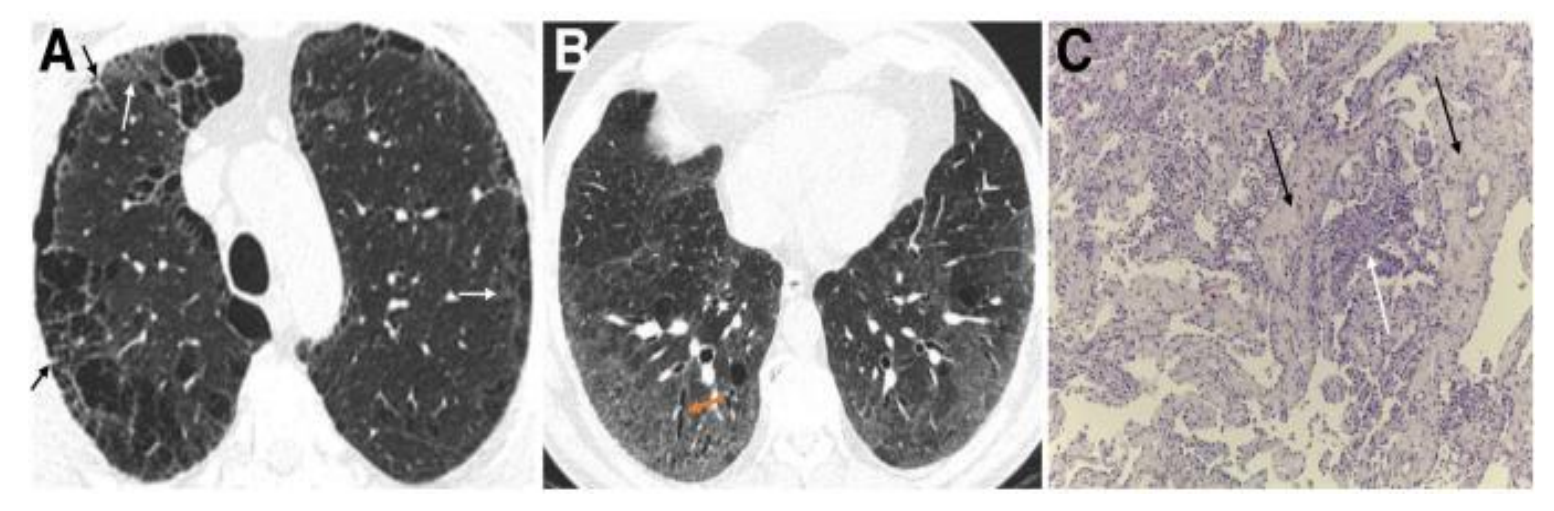

Fig. 15. Combination of $A E F$ and $D I P .^{28}$

The upper lobe shows the CLE and PLE shown with a picture of rethulation (black arrow) and patchy groundglass oppasitas (white arrow) (figure 15A). Groundglass opacity accompanied by scattered cystic formation, mild reticulation and bronchiectasis (orange arrow) indicates the presence of underlying fibrosis (figure 15B). There appears uniform alveolar septa wall thickening due to collagen deposits (black arrow) (Figure 15C). ${ }^{28}$

\subsection{Mixed smoking-related disorder}

Often lung disease due to cigarette exposure gives overlapping or combined features such as the presence of RBILD with DIP or DIP with PLCH, but there are also other features that can be found, namely the presence of emphysema and a fibrosis disorder called combined pulmonary fibrosis and emphysema (CPFE) ${ }^{22}$ 



Fig. 16. Combined pulmonary fibrosis and emphysema $(C P F E){ }^{28}$

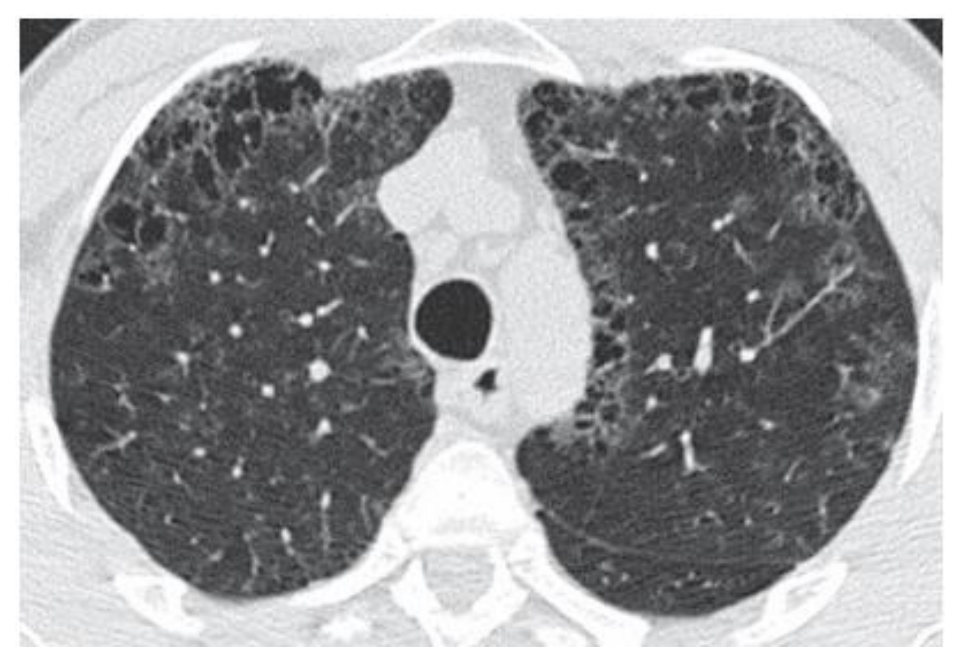

Fig. 17. The combination of groundglass, reticular and honeycomb opacities, which on histo PA can be a combination of RBILD, interstitial fibrosis and emphysema. ${ }^{20}$

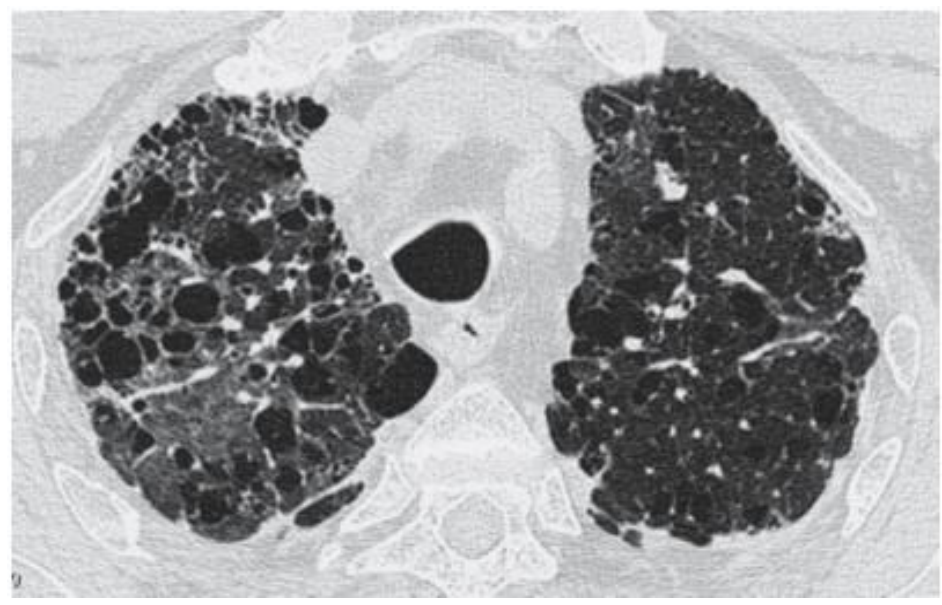


Fig.18. Combination of groundglass, honeycomb, cystic airspace and emphysema. ${ }^{20}$

\subsection{Large airways abnormalities in cigarette smokers}

Smoking not only causes subtle changes in the small airways such as bronchiolitis but also the moderate and large airways. Chronic bronchitis is the most common disorder of the large airways. Cigarettes and other irritants can cause chronic inflammation of the airways leading to hypertrophy of the mucous glands, leading to excessive secretion of sputum and squamous epithelial metaplasia and chronic inflammatory cell infiltration of the bronchial walls. On the HRCT image, bronchial wall thickening was found. ${ }^{29}$

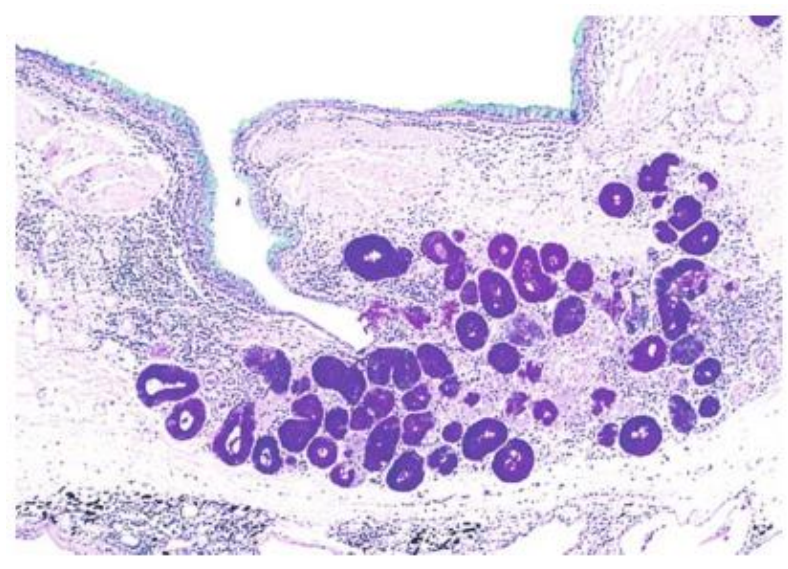

Fig. 19. PA histo image of chronic bronchitis with Alcian Blue PAS staining showed hypertrophy of the submucosal glands and increased goblet cells.. ${ }^{20}$

COPD is a progressive and irreversible air flow limited disease that often has the same features as bronchiolitis, chronic bronchitis and emphysema. COPD can also be found in the presence of air trapping, pneumothorax and bullae. Emphysema is a damage of the respiratory tract distal to the presence of terminal bronchioles that still survive and at a more severe level, damage to the lobules can occur. ${ }^{28}$

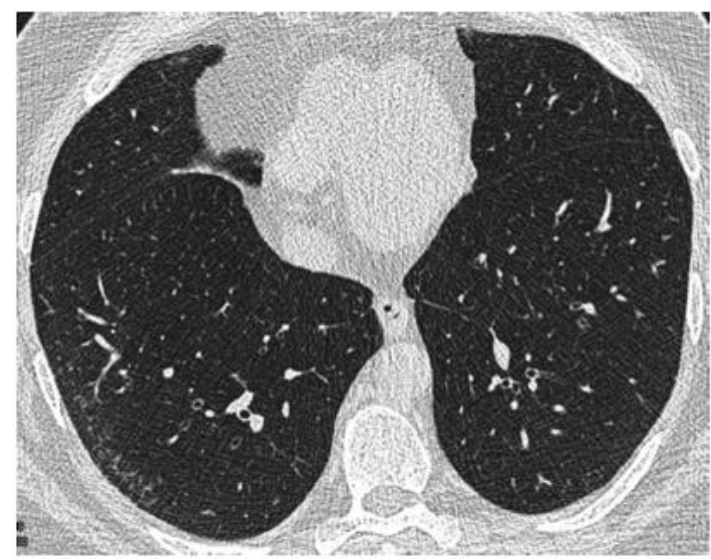

Fig. 20. Image of HRCT in a smoker, there is unspecified thickening of the bronchial walls and a smooth reticular pattern in the right lower lobe. ${ }^{20}$ 


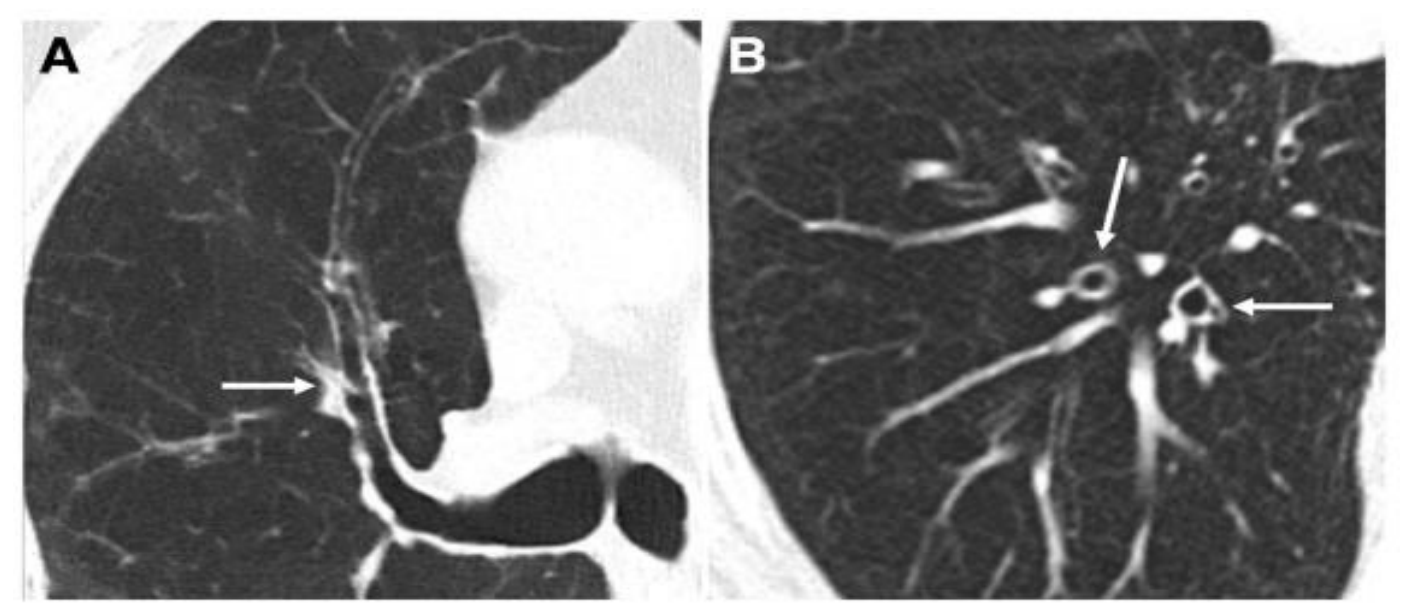

Fig. 21. Thickening of the bronchial wall in chronic bronchitis (white arrow) ${ }^{28}$

\section{Conclusion}

Cigarette smoke not only causes inflammation and damages the epithelium of the large respiratory tract but also the small airways and lung parenchyma. COPD (including chronic bronchitis and emphysema) is one of the most common lung diseases and causes death due to smoking. Lung disease related with smoking in addition to providing a mass image can also provide an interstitial picture such as Langerhans cell histiocytosis, bronchiolitis, desquamative interstitial pneumonitis and interstitial fibrosing lung disease. radiological picture in lung disease caused by cigarette smoke can also occur in combination. Although the radiological picture / image of computerized tomography can provide adequate information, a comprehensive diagnostic by combining clinical symptoms and histopathological features will be quite meaningful, especially for overlapping cases. 


\section{References}

1. Caminati A, Harari S. Smoking-related Interstitial Pneumonias and Pulmonary Langerhans Cell Histiocytosis. Proc Am Thorac Soc. 2006;3:299-306.

2. Susanto AD, Fitriani F, Ikhsan M, Antariksa B, Hudoyo A, Mansyur AK, et al. Berhenti Merokok : Pedoman Penatalaksanaan untuk Dokter di Indonesia. Jakarta: Perhimpunan Dokter Paru Indonesia (PDPI). 2011.

3. Sitepoe M. Kekhususan rokok indonesia: Mempermasalahkan PP no. 81 tahun 1999 tentang pengamanan rokok bagi kesehatan. Jakarta: Gramedia Pustaka Utama. 2000.

4. Thielen A, Klus H, Muller L. Tobacco smoke: Unraveling a controversial subject. Experimental and Toxicologic Pathology. 2008;60:141-156.

5. Valavanidis A, Vlachogianni T, Fiotakis K. Tobacco Smoke: Involvement of Reactive Oxygen Species and Stable Free Radicals in Mechanisms of Oxidative Damage, Carcinogenesis and Synergistic Effects with Other Respirable Particles. Int J Environ Res Public Health. 2009;6:445-462.

6. World Health Organization. A guide for tuberculosis patients to quit smoking. Geneva: World Health Organization (WHO).2014.

7. Dinn WM, Aycicegi A, Harris CL. Cigarette smoking in a student sample: Neurocognitive and clinical correlates. Addictive Behaviors. 2004;29:107-126.

8. McNulty W, Usmani OS. Techniques of assessing small airways dysfunction. European Clinical Respiratory Journal. 2014;1:1-17.

9. Bohadana A, Teculescu D, Martinet Y. Mechanisms of chronic airway obstruction in smokers. Respiratory Medicine. 2004;98:139-151.

10. Finkelstein R, Fraser RS, Ghezzo H, Cosio M. Alveolar Inflammation and its Relation to Emphysema in Smokers. Am J Respir Crit Care Med. 1995;152:1666-1672.

11. Verra F, Lebargy F, Berbaudin JF, Escudier E, Bignon J, Cremoux HD. Ciliary Abnormalities in Bronchial Epithelium of Smokers, Ex-smokers, and Non-smokers. Am J Respir Crit Care Med. 1995;151:630-634.

12. Domagala-Kulawik J. Effects of Cigarette Smoke on the Lung and Systemic Immunity. Journal of Physiology and Pharmacology. 2008;59(6):19-34.

13. Baraldo S, Turato G, Saetta M. Pathophysiology of the Small Airways in Chronic Obstructive Pulmonary Disease. Respiration. 2012;84:89-97.

14. Ekberg-Jansson A, Anderson B, Bake B, Boijsen M, Enanden I, Rosengren A, et al. Neutrophil-associated activation markers in healthy smokers relates to a fall in DLCO and to emphysematous changes on high resolution CT. Respiratory Medicine. 2001;95:363-373

15. Saetta M, Turato G, Facchini FM, Corbino L, Lucchini RE, Casoni G, et al. Inflammatory Cells in the Bronchial Glands of Smokers with Chronic Bronchitis. Am J Respir Crit Care Med. 1997;156:1633-1639.

16. O'shaughnessy TC, Ansari TW, Barnes NC, Jeffery PK. Inflammation in Bronchial Biopsies of Subjects with Chronic Bronchitis: Inverse Relationship of CD8+ T Lymphocytes with FEV1. Am J Respir Crit Care Med. 1997; 155:852-857.

17. Martin C, Frija J, Burgel PR. Dysfunctional lung anatomy and small airways degeneration in COPD. International Journal of COPD. 2013;8:7-13.

18. Hogg JC. Lung structure and function in COPD. Int J Tuberc Lung Dis. 2008;12(5):467-479. 
19. Saetta M, Ghezzo H, Kim WD, King M, Angus GE, Wang NS, et al. Loss of Alveolar Attachments in Smokers: a Morphometric Correlate of Lung Function Impairment. Am Rev Respir Dis. 1985;132:894-900.

20. Hansell DM, Wells AU. Smoking-related small airways and interstitial lung disease, in CT of the Airways, edited by Boiselle P and Lynch DA. Humana Press. 2008;14:325-350.

21. Myers JL, Veal CF, Shin MS, Katzenstein ALA. Respiratory bronchiolitis causing interstitial lung disease: a clinico-pathologic study of six cases. Am Rev Respir Dis. 1987;135:880-884.

22. Fraig M, Shreesha U, Savici D, Katzenstein AL. Respiratory bronchiolitis: a clinicopathologic study in current smokers, ex-smokers, and never-smokers. Am J Surg Pathol. 2002;26:647-653.

23. Sieminska A, Kuziemski K. Respiratory bronchiolitis-interstitial lung disease. Orphanet Journal of Rare Diseases. 2014;9(1):106-113.

24. Elkin SL, Nicholson AG, Du Bois RM. Desquamative interstitial pneumonia and respiratory bronchiolitisassociated interstitial lung disease. Semin Respir Crit Care Med. 2001;22(4):387-398.

25. Veeraraghavan S, Latsi PI, Wells AU, Pantelidis P, Nicholsin AG, Colby TV, et al. BAL findings in idiopathic nonspecific interstitial pneumonia and usual interstitial pneumonia. Eur Respir J. 2003;22:239-244.

26. Mastora I, Remy-Jardin M, Sobaszek A, Boulenguez C, Remy J, Edme JL. Thin-section CT finding in 250 volunteers: assessment of the relationship of CT findings with smoking history and pulmonary function test results. Radiology. 2001;218(3):695-702.

27. Myers JL, Aubry MC. Pulmonary langerhans cell histiocytosis: what was the question?. Am J Respir Crit Care Med. 2002;166:1419-1421.

28. Sousa C, Rodrigues M, Carvalho A, Viamonte B, Cunha R, Guimaraes S, et al. Diffuse smoking-related lung diseases: insights from a radiologic-pathologic correlation. Springer Open. 2019;10(73):1-13.

29. Matsuoka S, Uchiyama K, Shima H, Ueno N, Oish S, Nojiri Y. Bronchoarterial ratio and bronchial wall thickness on high-resolution $\mathrm{CT}$ in asymptomatic subjects: correlation with age and smoking. Am J Roentgenol. 2003;180:513-518. 